\title{
Research Paper: Dispatcher Criteria and Therapeutic Measurement by Air Emergency Ambulance of Kurdistan Province, Iran, 2017
}

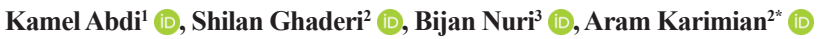 \\ 1. Department of Anesthesiology, School of Paramedical Sciences, Kurdistan University of Medical Sciences, Sanandaj, Iran. \\ 2. Department of Emergency Medical Sciences, School of Paramedical Sciences, Kurdistan University of Medical Sciences, Sanandaj, Iran. \\ 3. Social Determinants of Health Research Center, Research Institute for Health Development, Kurdistan University of Medical Sciences, Sanandaj, Iran.
}

\begin{tabular}{|c|c|}
\hline \multirow{2}{*}{$\begin{array}{l}\text { Use vour device to scan } \\
\text { and read the artice online }\end{array}$} & \\
\hline & Citation Abdi K, Ghaderi Sh, Nuri B, Karimian A. Dispatcher Criteria and Therapeutic Measurement by Air Emergency \\
\hline Fistis & $\begin{array}{l}\text { Ambulance of Kurdistan Province, Iran, 2017. Health in Emergencies and Disasters Quarterly. 2019; 4(2):63-70. http://dx.doi. } \\
\mathrm{org} / 10.32598 / \mathrm{hdq} .4 .2 .63\end{array}$ \\
\hline 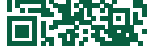 & doij http://dx.doi.org/10.32598/hdq.4.2.63 \\
\hline
\end{tabular}

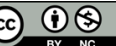

Article info:

Received: 10 May 2018

Accepted: 25 Oct 2018

Available Online: 01 Jan 2019

\section{Keywords:}

Trauma, Emergency,

Accidents, Injuries

\begin{abstract}
A B S T R A C T
Background: How to manage patients, transmission times, and therapeutic measurement executed during air transmission can improve training, protocols, and management decisions. The current study aimed at investigating the dispatch criteria and the way of handling patients during transport by air emergency medical services of Kurdistan Province, Iran, in 2017.
\end{abstract}

Materials and Methods: In the current study, information of patients transported by air emergency ambulance of Kurdistan Province in 2017 was collected from the recorded mission forms. To analyze the information, version 12 of STATA software was employed. Descriptive statistics was used to analyze the qualitative variables and draw frequency distribution table and mean and standard deviation to utilize quantitative variables.

Results: Out of 50 transported patients, trauma caused by traffic accidents was the most important cause of patient transport (38\%). In terms of clinical symptoms, weakness and lethargy and decreased consciousness were the most common symptoms. The most important therapeutic measures executed during transport were oxygen therapy, various body fixations, and serum therapy, respectively. The average time spent at scene was 10.7 minutes and the mean total mission time was 93.72 minutes with a standard deviation of 45.53 .

Conclusion: The results of the study indicated that the air emergency performance of Kurdistan Province was desirable in terms of dispatch criteria, time of transport and treatment during transportation, but there were weaknesses in the administration of medications during transportation and recording missions and measures in the specific sheets (forms).

\section{* Corresponding Author:}

Aram Karimian, MSC

Address: Department of Emergency Medical Sciences, School of Paramedical Sciences, Kurdistan University of Medical Sciences, Sanandaj, Iran

E-mail:e.sadri@uma.ac.ir 


\section{Introduction}

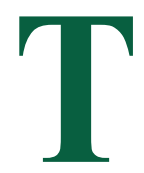

rauma is one of the most important and complex issues of the health care systems worldwide [1]. It is one of the leading causes of death in people 46 years old and younger, and one of the main causes of death occurred by incidents [2]. Natural incidents account for more than 3.9 million deaths and more than 138 million disabilities each year worldwide. Major incidents are events that require a medical response beyond the usual responses. These events are usually heterogeneous and different, and remain a challenge for medical emergencies [3].

It is estimated that by 2020 , one in 10 people die as a result of trauma and injury [4]. Medical emergency services can have immediate access to major incident scenes to treat patients promptly and take the necessary medical equipment to the scene [5]. Helicopter is a very necessary tool to manage major incidents and bring specialized teams and equipment to incident scenes. It is also used to transport patients, investigate the accident area as well as overhead surveillance.

When the incident scene is inaccessible, helicopters may be the only way to transfer personnel, equipment, and patients [6-8]. The first recorded use of a helicopter dates back to 1945, when it was used to quickly transport wounded soldiers of the Battle in Burma [9, 10]. After the first use of helicopters for military purposes in the Korean War to evacuate soldiers from the battlefield, helicopters were introduced in the USA medical emergencies in the early 1970s for civilian use, and then entered high-income countries and became a Helicopter Emergency Medical Service (HEMS) [11].

The employment of helicopter has several advantages including rapid transfer, transferring patient to a hospital instead of the nearest emergency department, using experienced personnel on the scene, and accessing incident locations not accessible by road. They also have some disadvantages: costly use, inability to fly in bad weather conditions or at night, and inability to perform some missions such as active delivery [12]. Although a number of studies show a decrease of $21 \%$ to $52 \%$ in mortality rates [13] and a survival increase of $12-40 \%$ in helicopter missions compared with road ambulances [6].

The employment of helicopters in densely populated urban areas whose usefulness is not clear, is still controversial. Moreover, since fewer studies are conducted in Iran on effectiveness of treatment and reduction of death rate in major incidents following the employment of air ambulance, the current study aimed at evaluating the injured ones transported by HEMS department in Kurdistan Province, Iran and the therapeutic measures taken during the transport.

\section{Materials and Methods}

The current cross sectional, retrospective study was conducted on a population consisting of all patients transported by the HEMS department of Kurdistan Province in 2017. The special geographical conditions and mountainous roads in Kurdistan Province delay the transfer of injured people to the hospital, especially in winter.

The employment of the air ambulance can reduce this time to one-fourth of time needed for the road ambulance transfer. Hence, HEMS department in Kurdistan Province was established in 2017 to reduce the transfer time of injured people and provide more favorable treatment services. The department uses a single-engine helicopter (ALOUETTE ) with the world's most important medical equipment. The helicopter has the ability to land on a slope due to having wheels and can cover the entire Kurdistan Province. In addition to emergency medical technicians working in the HEMS department, about 200 hospital staff and social workers in rural homes have received special training. The inclusion criteria in the current study were the patients transported by the HEMS department by the end of 2017, and exclusion criteria were those having incomplete EMS form.

After obtaining approval from the Ethics Committee of Kurdistan University of Medical Sciences and obtaining permission from the university, researcher referred to the EMS center of the province. After explaining the research goals and assuring the authorities about the confidentiality of their information, data were collected at two stages.

At the first stage, data were recorded in the computer center including number of transported patients, number of missions, time of dispatch, and transport period, and the time of arrival to hospital was also evaluated. At the second stage, information were recorded in Emergency Medical Services (EMS) form including age of the injured person, gender, incident type, incident place, treatment measures, medications, injury status, and place the patient was transported. Extracted data entered in a researcher-made checklist for each injured person.

The checklist included demographic information of the injured person, incident type, incident location, treat- 
ment measures, medications, and the location the patient was transported. This checklist was given to the faculty members of the Department of Emergency Medicine at Kurdistan University of Medical Sciences, and their corrective feedback were considered in the checklist and then validated. At the end, the collected data were analyzed with STATA version 12 software using descriptive statistics (frequency for qualitative variables and mean for quantitative variables) at a 95\% confidence interval.

\section{Results}

Of 50 patients transported by HEMS in 2017, totally $68 \%$ were male and $32 \%$ female. Most of them were within the age range of $20-30$ years; $80 \%$ of the missions were attributed to pre-hospital emergency care and the rest were performed between hospitals (transferring patients to a specialized hospital). Majority of patients $(72 \%)$ were transferred to the Kosar Hospital in Sanandaj (Table 1).

Table 2 presents mean and standard deviation of transport period. According to data shown on Table 2, the mean of on-scene time was 10.7 minutes and the mean total mission time was $93.72 \pm 45.53$ minutes. Car accident was the leading cause for transporting patients $(38 \%)$ followed by falling from the heights.
Other reasons were high-risk pregnancy, stroke, being shot, loss of consciousness, and pancreatitis, respectively. In terms of clinical signs, weakness and fatigue was the most common symptom among transported patients $(28 \%)$. The other most common symptoms were disorders of consciousness, bleeding, chest pain, abdominal pain, nausea, and vomiting (Table 3).

The most common medical treatment provided by medical emergency technicians during missions was oxygen therapy, which was performed on $92 \%$ of patients followed by limbs fixation $(88 \%)$, spinal fixation $(86 \%)$, and head and neck fixation (82\%). Serum therapy was the most common invasive measure $(86 \%)$. Needle tracheostomy $(\mathrm{n}=1)$ as well as electroconvulsive therapy and cardiopulmonary resuscitation $(n=2)$ were the least common therapeutic measures. For all patients, vital signs, lung rhythm, cardiac auscultation, and cardiovascular rhythm were checked by medical emergency technicians (Table 4).

\section{Discussion}

According to the results of the current study, the trauma caused by car accidents was the leading cause of transporting patients by HEMS department in Kurdistan followed by falling from heights. In the study of

Table 1. Demographic characteristics of the transported patients, mission type, and the location the patient was transported

\begin{tabular}{|c|c|c|}
\hline \multicolumn{2}{|c|}{ Variable } & \multirow{2}{*}{$\begin{array}{l}\mathbf{N}(\%) \\
16(32)\end{array}$} \\
\hline \multirow{3}{*}{ Gender } & Female & \\
\hline & & \\
\hline & Male & $34(68)$ \\
\hline \multirow{5}{*}{ Age, yr } & $<20$ & $4(8)$ \\
\hline & $20-30$ & $14(28)$ \\
\hline & $31-40$ & $13(26)$ \\
\hline & $41-50$ & $10(20)$ \\
\hline & $>50$ & $9(18)$ \\
\hline \multirow{3}{*}{ Mission type } & Between hospitals & $10(20)$ \\
\hline & & \\
\hline & Pre-hospital & $40(80)$ \\
\hline \multirow{4}{*}{ The location the patient w } & Kosar Hospital & $36(72)$ \\
\hline & Towhid Hospital & $12(24)$ \\
\hline & Besat Hospital in Hamedan & $1(2)$ \\
\hline & Imam Reza Hospital in Tabriz & 1(2) \\
\hline
\end{tabular}


Table 2. Mean $\pm S D$ of transport period

\begin{tabular}{|c|c|}
\hline Variable & Mean \pm SD \\
\hline Interval & $21.46 \pm 14.12$ \\
\hline On-scene time & $10.7 \pm 6.56$ \\
\hline Total & $93.72 \pm 45.53$ \\
\hline
\end{tabular}

Alamdari et al. (2010), that presented demographic characteristics of the patients transferred by EMS helicopter to Imam Khomeini Hospital in Tehran in 2010, trauma resulting from traffic accidents were the most common cause of HEMS transfer [14]. In Norway, a retrospective study on HEMS performance from 2004 to 2013 showed that trauma $(29.6 \%)$ was the major reason for HEMS missions [15].

Table 3. Patient's chief complaints and clinical signs of the transported people

\begin{tabular}{|c|c|c|}
\hline \multicolumn{2}{|c|}{ Variable } & \multirow{2}{*}{$\begin{array}{l}\mathbf{N}(\%) \\
13(38)\end{array}$} \\
\hline \multirow{7}{*}{ Patient's chief complaint } & Car accident & \\
\hline & Pancreatitis & $1(2)$ \\
\hline & Falling & $13(26)$ \\
\hline & Loss of consciousness & $2(4)$ \\
\hline & High-risk pregnancy & $8(16)$ \\
\hline & Being shot & $3(6)$ \\
\hline & Stroke & $4(8)$ \\
\hline \multirow{2}{*}{ Conscious-related complications } & Yes & $10(20)$ \\
\hline & No & $40(80)$ \\
\hline \multirow{2}{*}{ Dizziness } & Yes & $3(6)$ \\
\hline & No & $47(94)$ \\
\hline \multirow{2}{*}{ Blurred vision } & Yes & $1(2)$ \\
\hline & No & 49(98) \\
\hline \multirow{2}{*}{ Abdominal pain } & Yes & $5(10)$ \\
\hline & No & $45(90)$ \\
\hline \multirow{2}{*}{ Bleeding } & Yes & $8(16)$ \\
\hline & No & $42(84)$ \\
\hline \multirow{2}{*}{ Nausea and vomiting } & Yes & $5(10)$ \\
\hline & No & $45(90)$ \\
\hline \multirow{2}{*}{ Sensory impairment } & Yes & $4(8)$ \\
\hline & No & $46(92)$ \\
\hline \multirow{2}{*}{ Chest pain } & Yes & $5(10)$ \\
\hline & No & $45(90)$ \\
\hline \multirow{2}{*}{ Weakness and fatigue } & Yes & $14(28)$ \\
\hline & No & $36(72)$ \\
\hline
\end{tabular}


Table 4. Therapeutic measures taken during the transport

\begin{tabular}{|c|c|c|}
\hline \multicolumn{2}{|c|}{ Variable } & \multirow{2}{*}{$\frac{\mathbf{N}(\%)}{2(4)}$} \\
\hline \multirow{2}{*}{ Electroconvulsive therapy } & Yes & \\
\hline & No & $48(96)$ \\
\hline \multirow{2}{*}{ Cardiopulmonary resuscitation } & Yes & $2(4)$ \\
\hline & No & $48(96)$ \\
\hline \multirow{2}{*}{ Advanced airway management } & Yes & $3(6)$ \\
\hline & No & $47(94)$ \\
\hline \multirow{2}{*}{ Basic airway management } & Yes & $3(6)$ \\
\hline & No & $47(94)$ \\
\hline \multirow{2}{*}{ Needle tracheostomy } & Yes & $1(2)$ \\
\hline & No & $49(98)$ \\
\hline \multirow{2}{*}{ Respiratory support } & Yes & $8(16)$ \\
\hline & No & $42(84)$ \\
\hline \multirow[b]{2}{*}{ Suction } & Yes & $4(8)$ \\
\hline & No & $46(92)$ \\
\hline \multirow{2}{*}{ Monitoring } & Yes & $36(72)$ \\
\hline & No & $14(28)$ \\
\hline \multirow{2}{*}{ Head and neck fixation } & Yes & $41(82)$ \\
\hline & No & $9(18)$ \\
\hline \multirow{2}{*}{ Spinal fixation } & Yes & $42(84)$ \\
\hline & No & $8(16)$ \\
\hline \multirow{2}{*}{ Pelvic fixation } & Yes & $39(78)$ \\
\hline & No & $11(22)$ \\
\hline \multirow{2}{*}{ Limbs fixation } & Yes & $44(88)$ \\
\hline & No & $6(12)$ \\
\hline \multirow{2}{*}{ Serum therapy } & Yes & $43(86)$ \\
\hline & No & $7(14)$ \\
\hline \multirow{2}{*}{ Oxygen therapy } & Yes & $46(92)$ \\
\hline & No & $4(8)$ \\
\hline \multirow{2}{*}{ Bleeding control dressing } & Yes & $31(62)$ \\
\hline & No & $19(38)$ \\
\hline \multirow{2}{*}{ Checking lung rhythm } & Regular & 49(98) \\
\hline & Irregular & $1(2)$ \\
\hline \multirow{2}{*}{ Cardiac auscultation } & Normal sounds & $49(98)$ \\
\hline & Additional sounds & $1(2)$ \\
\hline \multirow{2}{*}{ Checking cardiovascular rhythm } & Regular & $49(98)$ \\
\hline & Irregular & $1(2)$ \\
\hline
\end{tabular}


This issue demonstrates the need for further studies, accurate evaluation, and presentation of executive solutions to reduce road accidents. The use of HEMS, especially in mountainous areas, greatly reduces the time of transporting traumatic patients to medical centers; which accordingly, the rate of mortality also decreases [16, 17]. The mean waiting time of the patient in the current study was 21.46 minutes. This time refers to interval between contacting with the emergency center and arrival on scene. In the study of Shojamoradi et al. (2008) on patients transported by HEMS in Tehran, the mean waiting time was 17 minutes. Due to the wide areas covered by the HEMS department of Kurdistan, 46.17 minutes seems appropriate [18].

In the current study, it was also reported that mean total HEMS mission time was 93.72 minutes. One of the reasons for this long time may be the transport of about $90 \%$ of patients from all areas of the province to Sanandaj health care centers, which is expected to be decreased in the future after construction of a helicopter pad at the hospitals of four cities in the province. The mean on-scene-time in the current study was 10.7 minutes. On-scene-time depends on several factors including type of accident (trauma or cardiac), severity of injury, therapeutic measures (such as fixation, intubation, etc.), and the patient transportation type [19].

Given that the most of transported patients were traumatic, this time is acceptable. The region climate and geographical conditions also affected HEMS mission time [20]. Considering that most of the HEMS missions in the study were conducted in autumn and winter (from September 2017 to the end of the year), the reported mission time is acceptable. The therapeutic measures taken by the emergency medical technician during the HEMS mission depended on the type of incident and the severity of injuries. Regarding the fact that the main reason for transport by HEMS in the current study was trauma, the most taken measures were related to the fixation of various body organs. In some studies conducted in Iran $[14,19]$.

Therapeutic interventions such as oxygen therapy, serum therapy, fixation, etc. were more general and less specialized measures such as tracheostomy, cardiopulmonary resuscitation, etc. were taken, although such measures are more common in the developed countries [21, 22]. Therefore, holding specialized training and practical workshops on the management of traumatic and heart patients during the transport with an EMS helicopter is recommended. Moreover, prescribing medication during missions was very limited. The reason can be attributed to the limitation of medical emergency technicians for drug injection and inadequate access to emergency physicians. With the advent of digital and remote telecommunication systems, this problem can be resolved in the close future.

Overview of the dispatch criteria indicates that the HEMS activation and HEMS dispatches depend not only on the national and international criteria, but also on the organizational factors such as the education of the dispatcher and the EMS personnel as well as the familiarity with the dispatch criteria [23]. The results of the study revealed that major dispatches was due to incidents, penetrating traumas, heart attacks, high-risk pregnancies, and medical emergencies in mountainous areas. According to the related studies $[23,24]$, the HEMS missions were in accordance with national and international standards.

\section{Conclusion}

The performance of HEMS department in Kurdistan Province was favorable in terms of dispatch criteria, duration of transfer, and treating patients during transportation; however, there were some weaknesses in the administration of medication during transport and recording the information in the HEMS mission form. In order to improve the performance of HEMS, the development of helicopter pads in other towns, and holding specialized training courses for HEMS personnel are recommended.

\section{Ethical Considerations}

\section{Compliance with ethical guidelines}

The study was approved by the Ethics Committee of Kurdistan University of Medical Sciences (Ethical code: IR.MUK.REC.1397.85).

\section{Funding}

The Research Committee of Kurdistan University of Medical Sciences has supported this research.

\section{Authors contributions}

All authors contributed in preparing this article.

\section{Conflict of interest}

The authors declared no conflict of interest.

\section{Acknowledgements}

Authors would like to thank the Deputy of Research and Technology of Kurdistan University of Medical Sciences, 
as well as managers and personnel of Helicopter Emergency Medical Service Center in Kurdistan Province for their valuable cooperation.

\section{References}

[1] Bouzat P, Ageron FX, Brun J, Levrat A, Berthet M, Rancurel $\mathrm{E}$, et al. A regional trauma system to optimize the pre-hospital triage of trauma patients. Critical Care. 2015; 19(1):111. [DOI:10.1186/s13054-015-0835-7] [PMID] [PMCID]

[2] Rhee P, Joseph B, Pandit V, Aziz H, Vercruysse G, Kulvatunyou $\mathrm{N}$, et al. Increasing trauma deaths in the United States. Annals of Surgery. 2014; 260(1):13-21. [DOI:10.1097/ SLA.0000000000000600] [PMID]

[3] LaGrone L, Riggle K, Joshipura M, Quansah R, Reynolds T, Sherr K, et al. Uptake of the world health organization's trauma care guidelines: A systematic review. Bulletin of the World Health Organization. 2016; 94(8):585-98C. [DOI:10.2471/ BLT.15.162214] [PMID] [PMCID]

[4] Galvagno Jr SM, Sikorski R, Hirshon JM, Floccare D, Stephens C, Beecher D, et al. Helicopter emergency medical services for adults with major trauma. Cochrane Database of Systematic Reviews. 2013; 28; (3):CD009228. [DOI:10.1002/14651858. CD009228.pub2]

[5] Aylwin CJ, Konig TC, Brennan NW, Shirley PJ, Davies G, Walsh MS, et al. Reduction in critical mortality in urban mass casualty incidents: Analysis of triage. The Lancet. 2006; 368(9554):2219-25. [DOI:10.1016/S0140-6736(06)69896-6]

[6] Assa A, Landau DA, Barenboim E, Goldstein L. Role of air-medical evacuation in mass-casualty incidents-atrain collision experience. Prehospital and Disaster Medicine. 2009; 24(3):271-6. [DOI:10.1017/S1049023X00006920] [PMID]

[7] Butler DP, Anwar I, Willett K. Is it the H or the EMS in HEMS that has an impact on trauma patient mortality? A systematic review of the evidence. Emergency Medicine Journal. 2010; 27(9):692-701. [DOI:10.1136/emj.2009.087486] [PMID]

[8] Spano SJ, Campagne D, Stroh G, Shalit M. A lightning multiple casualty incident in sequoia and kings canyon national parks. Wilderness \& Environmental Medicine. 2015; 26(1):4353. [DOI:10.1016/j.wem.2014.06.010]

[9] Vercruysse GA, Friese RS, Khalil M, Ibrahim-Zada I, Zangbar B, Hashmi A, et al. Overuse of helicopter transport in the minimally injured: A health care system problem that should be corrected. Journal of Trauma and Acute Care Surgery. 2015; 78(3):510-5. [DOI:10.1097/TA.0000000000000553] [PMID]

[10] Carter G, Couch R, O'Brien DJ. The evolution of air transport systems: A pictorial review. Journal of Emergency Medicine. 1988; 6(6):499-504. [DOI:10.1016/0736-4679(88)90408-8]

[11] Johnsen AS, Fattah S, Sollid SJM, Rehn M. Utilisation of helicopter emergency medical services in the early medical response to major incidents: A systematic literature review. BMJ Open. 2016; 6(2):e010307. [DOI:10.1136/bmjoe pen-2015-010307] [PMID] [PMCID]
[12] Black JJM, Ward ME, Lockey DJ. Appropriate use of helicopters to transport trauma patients from incident scene to hospital in the United Kingdom: An algorithm. Emergency Medicine Journal. 2004; 21(3):355-61. [DOI:10.1136/ emj.2002.004473] [PMID] [PMCID]

[13] Baxt WG, Moody P. The Impact of a Rotorcraft Aeromedical Emergency Care Service on Trauma Mortality. The Journal of the American Medical Association. 1983; 249(22):304751. [DOI:10.1001/jama.1983.03330460029027]

[14] Alamdari Sh, Kalantari Meibodi M, Mohammadi P, Kariman H. [Study of the demography of transferred patients to Tehran Imam Khomeini Hospital by relief helicopter (Persian)]. Quarterly Scientific Journal of Rescue and Relief. 2010; $1(4)$.

[15] Osteras O, Brattebø G, Heltne JK. Helicopter-based emergency medical services for a sparsely populated region: A study of 42,500 dispatches. Acta Anaesthesiologica Scandinavica. 2016; 60(5):659-67. [DOI:10.1111/aas.12673] [PMID] [PMCID]

[16] Nicholl JP, Brazier JE, Snooks HA. Effects of London helicopter emergency medical service on survival after trauma. British Medical Journal. 1995; 311(6999):217-22. [DOI:10.1136/ bmj.311.6999.217] [PMID] [PMCID]

[17] Brown JB, Gestring ML, Stassen NA, Forsythe RM, Billiar TR, Peitzman AB, et al. Geographic variation in outcome benefits of helicopter transport for trauma in the United States: A retrospective cohort study. Annals of Surgery. 2016; 263(2):406-12. [DOI:10.1097/SLA.0000000000001047] [PMID] [PMCID]

[18] Shojamoradi, M, Alavi, E, Zarrabi, B, Pilehvari, Z, Kaviani, A. [Evaluation of the patients transported by Tehran Helicopter Emergency Medical Service: The necessity of using appropriate triage criteria (Persian)]. Razi Journal of Medical Sciences. 2008; 15(59):99-106

[19] Østerås Ø, Heltne JK, Vikenes BC, Assmus J, Brattebø $\mathrm{G}$. Factors influencing on-scene time in a rural Norwegian helicopter emergency medical service: A retrospective observational study. Scandinavian Journal of Trauma, Resuscitation and Emergency Medicine. 2017; 25(1):97. [DOI:10.1186/ s13049-017-0442-5] [PMID] [PMCID]

[20] Chen X, Gestring ML, Rosengart MR, Peitzman AB, Billiar TR, Sperry JL, et al. Logistics of air medical transport: When and where does helicopter transport reduce prehospital time for trauma. The Journal of Trauma and Acute Care Surgery. 2018; 85(1):174-81. [DOI:10.1097/TA.0000000000001935] [PMID]

[21] Abe T, Nagano T, Ochiai H. Potential benefit of physicianstaffed helicopter emergency medical service for regional trauma care system activation: An observational study in rural Japan. Journal of Rural Medicine. 2017; 12(1):12-19. [DOI:10.2185/jrm.2919] [PMID] [PMCID]

[22] Sunde GA, Heltne JK, Lockey D, Burns B, Sandberg M, Fredriksen K, et al. Airway management by physician-staffed helicopter emergency medical services: A prospective, multicentre, observational study of 2,327 patients. Scandinavian Journal of Trauma, Resuscitation and Emergency Medicine. 2015; 7(23):57. [DOI:10.1186/s13049-015-0136-9] [PMID] [PMO CID]

[23] Wigman LD, van Lieshout EMM, de Ronde G, Patka P, Schipper IB. Trauma-related dispatch criteria for helicopter 
emergency medical services in Europe. International Journal of the Care of the Injured. 2011; 42(5):525-33. [DOI:10.1016/j. injury.2010.03.015] [PMID]

[24] Giannakopoulos GF, Bloemers FW, Lubbers WD, Christiaans HMT, van Exter P, De Lange-de Klerk ESM, et al. Criteria for cancelling Helicopter Emergency Medical Services (HEMS) dispatches. Emergency Medicine Journal. 2012; 29(7):582-6. [DOI:10.1136/emj.2011.112896] [PMID] 